\title{
A enunciação enquanto fenômeno integrador dos estudos discursivos e literários
}

\section{The enunciation as an integrating phenomenon of discursive and literary studies}

Doutor em Linguistica pela Pontifícia Universidade Católica do Rio Grande do Sul (PUCRS). Professor na Escola de Humanidades da Pontifícia Universidade Católica do Rio Grande do Sul, no Curso de Letras e no Programa de Pós Gradu,ça em Letras. Coordena o grupo de pesquisa (i) htps:/lrid orgo Dail: claudidelanoy@pucrs. br

Doutora em Linquística pela Universidade Federal da Paraiba (UFPB), Mestre em Linguística Aplicada pela Universidade do Vale do Rio dos Sinos (UNISINOS). Professora do curso de Letras e Programa de Pos-graduaçáo em Letras e Artes da Universidade do Estado do Amazonas (UEA). (i) htpi//orcidorg/0000-0002-5845-8079 E-mail: jucianecavalheiro@gmail.com

Doutoranda em Linguística no Programa de PósGraduação em Letras da Escola de Humanidades da Pontificia Universidade Catolica do Rio Grande do Sul (PPGL/PUCRS), com bolsa integral do Conselho Nacional de Desem bolsa in

E-mail: deboraboenavides@acadpurs

\author{
Cláudio Primo Delanoy \\ Pontifícia Universidade Católica do Rio Grande do Sul, Escola de Humanidades, \\ Programa de Pós-Graduação em Letras, Porto Alegre RS Brasil. \\ Juciane dos Santos Cavalheiro² \\ Universidade do Estado do Amazonas, Programa de Pós-Graduação em Letras e Artes, Manaus, AM, Brasil. \\ Débora Luciene Porto Boenavides ${ }^{3}$ \\ Pontifícia Universidade Católica do Rio Grande do Sul, Escola de Humanidades,
Programa de Pós-Graduação em Letras, Porto Alegre, RS, Brasil.
}

nvestigar a linguagem é também investigar o humano. Partimos do princípio de que a linguagem é a condição primeira da sociedade, pois é pelo discurso, enquanto expressão da linguagem, que interagimos socialmente. Sem linguagem não seria possível viver em sociedade. Dessa maneira, as pesquisas sobre linguagem em uso são relevantes na medida em que o discurso revela em si a própria sociedade: modos de perceber o outro, a si mesmo, o mundo, a vida. Segundo Benveniste, "A linguagem é para o homem um meio, na verdade, o único meio de atingir o outro homem, de lhe transmitir e de receber dele uma mensagem. Consequentemente, a linguagem exige e pressupõe o outro. A partir deste momento, a sociedade é dada com a linguagem" (BENVENISTE, 2006b, p.93). Se há linguagem, há sujeito; e, ao mesmo tempo, se há sujeito, há discurso, há enunciação. Portanto, estudar o discurso e a enunciação é estudar a própria humanidade.

Eis, indissociável a relação entre linguagem e sociedade, tal como vista por Benveniste. É por meio da linguagem que o ser humano, o eu, se constitui, e essa constituição também passa pelo outro. Pelo viés benvenistiano, não há como conceber o homem separado da linguagem. Ao escrever sobre o poder da palavra, diz-nos: "Não existe realmente poder mais alto, e todos os poderes do homem, sem exceção, pensemos bem nisso, decorrem desse. A sociedade não é possível a não ser pela língua; e, pela língua, também o indivíduo" (BENVENISTE, 2005, p. 27). 
Assim como Benveniste, Mikhail Bakhtin entende a linguagem como uma realidade definidora da própria condição humana, ao recuperar, por exemplo, o sujeito para o discurso, através do nós e do outro, mediante processo de subjetivação. Para Bakhtin, uma análise concreta da enunciação somente é possível se ela for entendida "como unidade contraditória e tensa de duas tendências opostas da vida": uma que centralize e outra que descentralize. É no "meio" dessas duas forças que a enunciação vive e se forma através de um "plurilinguismo dialogizado", ou seja, "anônimo e social como linguagem, mas concreto, saturado de conteúdo e acentuado como enunciação individual” (BAKHTIN, 2010, p. 82).

A linguagem é a possibilidade da subjetividade pelo fato de conter sempre as formas linguísticas apropriadas a sua expressão; já o discurso, ou seja, a língua assumida pelo homem que fala, sob a condição de intersubjetividade, é o único que torna possível a comunicação linguística. Assim como a linguagem - tal como entendida quando estudada por uma perspectiva enunciativa ou discursiva -, o universo estético não nasce a partir de uma relação reiterável de sinais axiologicamente neutros, mas de uma relação viva de consciências sociais. Sob essa perspectiva, elegemos a enunciação como tema deste número da Letrônica. Por enunciação entendemos a instância real da comunicação humana, em que um locutor se dirige a um interlocutor, num dado espaço-tempo, situado histórica e socialmente, visando a um propósito. Assim, abrimos espaço para a investigação da manifestação enunciativa em suas múltiplas faces, seja no campo da Linguística, seja no campo da Literatura. Nesse âmbito, foram reunidos textos que trabalhassem, de modo integrado, os estudos enunciativos e os literários, ambos apoiados na pesquisa sobre a linguagem em uso.

É de se sublinhar que o interesse pelo estudo da linguagem remonta aos alicerces da cultura ocidental. Sócrates, Platão, Aristóteles, para citar os filósofos mais conhecidos, lançaram as primeiras reflexões sobre a língua, a literatura, o teatro. Nascem, no período, as primeiras considerações sobre os gêneros literários e sobre classificações gramaticais. No entanto, ao longo de todo o período que antecede o século XX, o cerne motivador voltava-se para considerações filosóficas da linguagem, as gramáticas comparadas, os estudos filológicos. Não havia uma ciência linguística consolidada. Porém, a Linguística do século XX marcou-se, sobretudo, pelo cientificismo. Mais precisamente em 1916, aponta-se o início da Linguística moderna com a publicação do Curso de Linguística Geral, na França, a partir dos estudos feitos pelo linguista suíço Ferdinand de Saussure. É inaugurado um novo modo de estudar a língua: há um rompimento com estudos históricos, filológicos, filosóficos da linguagem e há a proposta de pesquisas da língua pela perspectiva sincrônica. Interessa-se pela organização da língua enquanto um sistema de signos, em que o sentido de uma palavra dar-se-ia em função de sua relação com outras palavras. Além disso, foi definido o objeto de estudo da Linguística, a língua enquanto sistema, um conjunto de convenções arbitrárias e compartilhadas pela sociedade. A Saussure é atribuído o início do Estruturalismo (embora o linguista não tenha usado essa expressão em seus cursos), corrente metodológica que reinou ao longo do 
século XX e ainda apresenta estudos consistentes até hoje. Os estudos ganharam tamanho impacto que influenciaram outras áreas como a teoria da literatura, a sociologia, a psicologia. No momento de alçamento da Linguística ao campo da Ciência, com objeto de análise definido e metodologia própria, as investigações sobre língua debruçam-se sobre o sistema e afastam-se do seu uso efetivo na comunidade de falantes.

Desse modo, os estudos científicos da Linguística e da Literatura foram historicamente separados por fronteiras metodológicas que comprometiam tentativas de diálogo entre eles. Atualmente, linguistas e teóricos da literatura interessam-se pela integração dos campos, sob a perspectiva de o discurso, literário ou não, ser manifestação da sociedade. No entanto, a parceria entre Linguística e Literatura não é nova. A integração das áreas constituiu as reflexões de Roman Jakobson (1896-1982), Mikhail Bakhtin (1895-1975), Valentin Voloshinov (1895-1936), Dominique Maingueneau, e também dos brasileiros Carlos Alberto Faraco, Sírio Possenti, Beth Brait, José Luiz Fiorin, entre outros. O potencial interdisciplinar, portanto, dos campos discursivos e enunciativos com outros campos de saber, a literatura, por exemplo, é patente se circunscrita à esfera do sujeito. Em termos literários, o ficcionista nomeia elementos através de interferências no campo da subjetividade. $O$ relato ficcional pode configurar-se como organizador da experiência subjetiva, na medida em que através dele é possível visualizar paradigmas sócio-espaço-temporais: como produtor de sentidos e revelador de ausência de sentido.

Apresentamos a enunciação como fenômeno integrador dos estudos discursivos e literários. Benveniste desenvolve o conceito a partir das reflexões saussurianas e define como "colocar em funcionamento a língua por um ato individual de utilização” (BENVENISTE, 2006a, p. 82). É o estudo da língua em seu funcionamento, submetida à enunciação. Segundo Bakhtin/Volochínov (2006, p. 47), os enunciados são campos de lutas sociais, de visões ideológicas distintas. Ao propor o princípio do dialogismo como fundador da linguagem, abarca de uma vez tanto os discursos ordinários quanto os literários. Segundo o pensador russo, nosso acesso ao mundo se dá sempre por meio de discursos já proferidos, inevitavelmente atravessados por outros discursos e marcados por tons avaliativos de verdade, de mentira, de seriedade, de desconfiança, etc. Logo, todo discurso inevitavelmente dialoga com outros discursos, e é a partir desse diálogo que ele se constitui. A impossibilidade de atingirmos os objetos do mundo senão por meio de discursos, segundo Bakhtin, aproxima-se do pensamento de Benveniste quando escreve: "A linguagem reproduz a realidade. Isso deve ser entendido da maneira mais literal: a realidade é produzida novamente por intermédio da linguagem” (BENVENISTE, 2005, p. 26). É nesse sentido que defendemos a importância dos estudos do discurso para entendermos a sociedade e, consequentemente, a nós mesmos.

A literatura faz-nos olhar a nós mesmos a partir do texto ficcional. $\mathrm{O}$ indivíduo constrói sua subjetividade num espaço social onde outras subjetividades surgem e marcam a sua especificidade. A subjetividade, portanto, tal como 
compreendido por Benveniste e Bakhtin, não se dá no limite do $e u$, mas "o eu em relação de reciprocidade com outros indivíduos, isto é, eu e outro, eu e tu" (BAKHTIN, grifos do autor, 2003, p. 407); e, para Benveniste, quando "eu" se apropria da língua, implica, necessariamente um "tu", pois "é numa realidade dialética que englobe os dois termos e os defina pela relação mútua que se descobre o fundamento linguístico da subjetividade” (BENVENISTE, 2005, p. 287).

Tendo como tema Enunciação e Literatura, este número da revista Letrônica reúne sete artigos concebidos sob a proposta de transitarem entre a Linguística e a Literatura, tomando como ponto de contato a enunciação.

O número é aberto pelo artigo "Entre Subjetividad y Alteridad en el Discurso Político en Prosa de Gabriela Mistral en la Década de 1930", de Gabriel Arturo Farias Rojas e Juciane dos Santos Cavalheiro, no qual, por meio da análise crítica do discurso político na prosa de Gabriela Mistral, é revelada uma nova narrativa sobre a primeira autora latino-americana a receber o Prêmio Nobel de Literatura, oposta à biografia monolítica de uma Mistral apolítica e conservadora, imposta desde o mito colonial do Chile Republicano.

Compõem ainda o número dois artigos que versam sobre a obra de Clarice Lispector. Em “'É tempo de morangos': argumentação, discurso e enunciação em A hora da estrela, de Clarice Lispector", Jacob do Santos Biziak insere a obra de Clarice Lispector em um novo contexto citacional e propõe-se a entender o "pensamento do feminino" (categoria proposta por Carla Rodrigues em diálogo com a obra de Jacques Derrida) no discurso de Lispector como prática política diante da realidade. Valdicléa Souza, em "O discurso sobre leitor na obra Água viva de Clarice Lispector: um passeio pelo bosque da interdiscursividade", investiga o funcionamento do discurso sobre o leitor através da voz do narrador-personagem na referida obra.

Carolina Knack, em seu artigo "O enlace entre a literatura e a linguística enunciativa Benvenistiana: palavras para fazer ouvir interrogações” reflete sobre a relação entre a literatura e a linguística enunciativa derivada dos postulados de Émile Benveniste. Tratando do texto teatral, o artigo de Mariano Nicolás Zucchi, "Una clasificación del discurso didascálico desde una perspectiva polifónica de la enunciación”, propõe uma classificação do discurso didascálico que aborde suas características linguísticas específicas.

Fechando o número, temos o artigo "Nos labirintos do tempo: a instituição do sujeito nostálgico sob um viés enunciativo", de Ernani Cesar de Freitas e Rafael da Silva Moura, que analisa a constituição do sujeito nostálgico no soneto Nostalgia, da poetiza portuguesa Florbela Espanca, mediante a relação intersubjetiva entre o locutor e o interlocutor. $\mathrm{O}$ número conta também com a resenha escrita por William Moreno Boenavides do livro Vološinov e a filosofia da linguagem de Patrick Sériot, traduzido por Marcos Bagno e publicado pela Parábola Editorial, em 2015.

Desejamos uma boa leitura! 


\section{Referências}

BAKHTIN, M. [VOLOCHINOV, V. N.]. Marxismo e filosofia da linguagem (1929). Trad. Michel Lahud e Yara Frateschi Vieira. 7. ed. São Paulo: Hucitec, 2006.

BAKHTIN, M. Metodologia das Ciências Humanas. In: Estética da criação verbal. Trad. Paulo Bezerra. 4. ed. São Paulo: Martins Fontes, 2003. p. 393-410.

BAKHTIN, M. O problema do conteúdo, do material e da forma na criação literária. In: Questões de literatura e de estética: a teoria do romance. Trad. Aurora F. Bernardini et al. 6. ed. São Paulo: Hucitec, 2010. p. 13-70.

BAKHTIN, M. O discurso no romance. In: Questões de literatura e de estética: a teoria do romance. Trad. Aurora F. Bernardini et al. 6. ed. São Paulo: Hucitec, 2010. p. 71-210.

BENVENISTE, E. Vista d'olhos sobre o desenvolvimento da linguística. In: Problemas de Linguística Geral I. 5. ed. São Paulo: Pontes, 2005a. p. 19-33.

BENVEnISTE, E. Da subjetividade na linguagem. Problemas de Linguística Geral I. 5. ed. São Paulo: Pontes, 2005b. p. $284-293$.

BENVENISTE, E. O aparelho formal da enunciação. In: Problemas de Linguística Geral II. 2. ed. São Paulo: Pontes, 2006 a. p. 81-90.

BENVENISTE, E. Estrutura da língua e estrutura da sociedade. In: Problemas de Linguística Geral II. 2. ed. São Paulo: Pontes, 2006b. p. 93-104. 